\title{
AVALIAÇÃO DE POPULAÇÕES DE POLINIZAÇÃO LIVRE, VARIEDADES COMERCIAIS E CRIOULAS DE MILHO EM DOIS MUNICÍPIOS DE ALAGOAS
}

\author{
Ruy Feitosa Falcão ${ }^{1}$, Paulo Vanderlei Ferreira² ${ }^{2}$ Antônio Barbosa da Silva Júnior ${ }^{3}$, Islan \\ Diego Espindula de Carvalho ${ }^{4}$, Jackson da Silva ${ }^{5 *}$, Douglas Ferreira dos Santos ${ }^{6}$
}

\footnotetext{
${ }^{1}$ Mestre em Produção vegetal. Universidade Federal de Alagoas (UFAL), Centro de Ciências Agrárias, Rio Largo - AL.

${ }^{2}$ Professor Titular. Universidade Federal de Alagoas (UFAL), Centro de Ciências Agrárias, Rio Largo - AL.

${ }^{3}$ Doutorando em Produção Vegetal. Universidade Federal de Alagoas (UFAL), Centro de Ciências Agrárias, Rio Largo - AL.

4 Doutorando em Agronomia - Melhoramento Genético de Plantas. Universidade Federal Rural de Pernambuco (UFRPE), Recife - PE.

${ }^{5}$ Mestrando em Agronomia - Agricultura. Universidade Estadual Paulista (UNESP), Faculdade de Ciências Agronômicas, Botucatu - SP. *Email do autor correspondente: jackson.silva.batalha @ gmail.com

${ }^{6}$ Graduando em Agronomia. Universidade Federal de Alagoas (UFAL), Centro de Ciências Agrárias, Rio Largo - AL.
}

RESUMO: O objetivo do presente trabalho foi avaliar o desempenho agronômico de populações de polinização livre, variedades comerciais e crioulas de milho em dois municípios de Alagoas. Esse trabalho foi conduzido no período de maio a outubro de 2013, nos municípios alagoanos de Santana do Ipanema e São José da Tapera. Os genótipos avaliados foram: Alagoano, Branca, São Luiz, Viçosense, Asa Branca, Assum Preto, Batité, Branca Crioula e Jaboatão. Foi utilizado o delineamento em blocos casualizados com três repetições. As variáveis mensuradas foram: diâmetro do colmo, altura de planta, altura de inserção de primeira espiga, empalhamento das espigas, número de fileiras de grãos, peso de cem grãos, rendimento de grãos e rendimento de matéria seca. As populações Alagoanas e as variedades crioulas apresentaram um porte mais alto, uma maior altura de inserção da primeira espiga e um maior diâmetro de colmo que as variedades comerciais, proporcionando um maior rendimento de matéria seca nos dois ambientes. Levando em consideração os dois ambientes, a população alagoana Branca e a variedade crioula Jaboatão apresentaram rendimento de matéria seca de superiores a $5.000 \mathrm{~kg} \mathrm{ha}^{-1}$, sendo a Branca o genótipo que apresentou dupla aptidão, se destacando dos demais genótipos.

Palavras-chave: Zea mays L. Rendimento de grão. Cultivares. Interação genótipos x ambientes.

\section{EVALUATION OF FREE POLLINATION POPULATIONS, COMMERCIALS AND CREOLE VARIETIES CORN IN TWO MUNICIPALITIES OF ALAGOAS}

\begin{abstract}
The objective of the present study was to evaluate the agronomic performance populations of free pollination, commercial varieties and maize varieties in two municipalities of Alagoas. This work was conducted from May to October 2013, in the Alagoas municipalities of Santana do Ipanema and São José da Tapera. The evaluated
\end{abstract}

Cultura Agronômica, Ilha Solteira, v.26, n.4, p.611-624, 2017 
genotypes were: Alagoano, Branca, São Luiz, Viçosense, Asa Branca, Assum Preto, Batité, Branco and Jabotão. A randomized complete block design with three replicates was used. The variables measured were: stalk diameter, plant height, first tenon insertion height, tenon mulching, number of rows of grains, weight of one hundred grains, grain yield and dry matter yield. In the Alagoas populations and creole varieties presented a higher size, a higher insertion height of the first tenon and a larger stem diameter than the commercial varieties, providing a higher yield of dry matter in both environments. Taking into account the two environments, the in the Alagoas population Branca and the Jabotão creole variety they presented dry matter yield of more than $5,000 \mathrm{~kg} \mathrm{ha}^{-1}$, being the Branca the genotype that presented dual aptitude, standing out of the other genotypes.

Key words: Zea mays L. Yield of grain. Cultivars. Interaction genotypes x environments.

\section{INTRODUÇÃO}

O milho (Zea mays L.) é uma cultura de grande importância econômica e social, fornecendo matéria prima para utilização direta na alimentação humana e animal, além de ser ingrediente da linha de produção da indústria de rações e de alimentos, fazendo parte da composição de diversos produtos: refrigerantes, cervejas, xaropes, sorvetes, biscoitos, óleo, papel, adesivos, salsichas entre outros (QUEIROZ et al., 2011).

Dessa forma, o milho é uma fonte de segurança alimentar e nutricional bastante interessante para as famílias dos pequenos agricultores. Em função disso, é uma importante fonte de carboidratos na mesa das famílias não só dos agricultores, mas também de toda população os pratos preparados com esse cereal (BECKER; ANJOS, 2010).

Em Alagoas, a agricultura familiar é a categoria responsável pela maior parte da produção de milho, onde o mesmo é cultivado em todas as microrregiões, sendo plantado em 75 dos 102 municípios, obtendo rendimento médio de $844 \mathrm{~kg} \mathrm{ha}^{-1}$. Essa média é considerada baixa, pois é bem inferior a produtividade nordestina que é de $2.500 \mathrm{~kg} \mathrm{ha}^{-1}$ que por sua vez, é inferior à média nacional da ordem de $5.259 \mathrm{~kg} \mathrm{ha}^{-1}$ observadas no ano de 2013 (IBGE, 2013).

Essa baixa produtividade é devido à predominância de sistema de produção que utiliza pouca ou nenhuma tecnologia, irregularidades climáticas que provocam muitas vezes as frustrações de safras, fatores culturais e econômicos, baixa densidade populacional, plantio consorciado com outras culturas, insuficiência de sementes selecionadas das variedades melhoradas na região, utilização de cultivares com baixo potencial produtivo e/ou baixa adaptabilidade quanto ao solo e clima, além do uso de variedades crioulas. Assim, uma alternativa para essa baixa produtividade passa pelo cultivo de genótipos produtivos e adaptados a cada ambiente, sendo necessário para isso a correta identificação desses genótipos (BRAMBILLA et al., 2009; MADALENA et al., 2009; VALDERRAMA et al., 2011).

Cultura Agronômica, Ilha Solteira, v.26, n.4, p.611-624, 2017 
O objetivo desse trabalho foi avaliar o desempenho agronômico de populações de polinização livre, variedades comerciais e crioulas de milho em dois municípios de Alagoas.

\section{MATERIAL E MÉTODOS}

Os dois experimentos foram conduzidos no período de maio a setembro de 2013. Um experimento foi implantado na área experimental do Instituto de Inovação para o Desenvolvimento Rural Sustentável de Alagoas - EMATER-AL, no município de Santana do Ipanema-AL, com altitude aproximada entre 300 a $400 \mathrm{~m}$ em relação ao nível do mar e apresenta as coordenadas geográficas de $9^{\circ} 24^{\prime} 13,2$ ' ' de latitude sul e $37^{\circ} 13^{\prime} 55,8^{\prime \prime}$ de longitude oeste. Já o outro experimento foi implantado numa propriedade rural, localizada no município de São José da Tapera-AL, com altitude aproximada 100 a $200 \mathrm{~m}$ em relação ao nível do mar, situado nas coordenadas 9³2'06,9 de latitude sul e 37²1'49,7' de longitude oeste (ALVARES et al., 2014).

Os municípios estão localizados na microrregião homogênea de Santana do Ipanema e segundo a classificação climática de Köppen apresenta o clima quente, semiárido, tipo estepe com chuvas concentradas no inverno. As temperaturas médias anuais estão próximas de $22{ }^{\circ} \mathrm{C}$ nos meses mais frios e $26^{\circ} \mathrm{C}$ nos meses mais quentes, com precipitação média anual de menos de $700 \mathrm{~mm}$. O solo é classificado como Neossolo Regolítico para área de São José da Tapera e associação de Argissolo Vermelho mais Neossolo Litólico em Santana do Ipanema (ALVARES et al., 2014).

Os genótipos avaliados foram: quatro populações de polinização livre desenvolvidas pelo Setor de Melhoramento Genético de Plantas do Centro de Ciências Agrárias da Universidade Federal de Alagoas (SMGP/CECA/UFAL): Viçosense, Alagoano, Branca e São Luiz; duas variedades comerciais desenvolvidas pela Empresa Brasileira de Pesquisa Agropecuária (EMBRAPA), recomendadas para o semiárido nordestino: Assum Preto e Asa Branca; e três Variedades Crioulas cultivadas por agricultores familiares alagoanos: Batité, Jabotão e Branco.

As sementes foram armazenadas em garrafa pet em câmera fria, até a implantação dos experimentos, em temperatura de $10{ }^{\circ} \mathrm{C}$ e umidade relativa do ar de $40 \%$, não sendo utilizado nenhum tratamento químico nas sementes. Antes da instalação dos experimentos, as sementes foram mantidas por três dias em condições de laboratório para que as sementes entrassem em equilíbrio com a temperatura e a umidade relativa do ar ambiente. Foi utilizado o delineamento em blocos casualizados, com 09 tratamentos em três repetições, totalizando 27 parcelas experimentais. Cada parcela foi constituída de 05 linhas de $5 \mathrm{~m}$ de comprimento, com espaçamento de $1 \mathrm{~m}$ entre linhas e 0,2 entre plantas. A área da parcela foi de $25 \mathrm{~m}^{2}$ com 25 plantas por linha e 125 por parcela. Para reduzir o efeito bordadura foram excluídas as duas linhas mais externas e duas plantas de cada extremidade das linhas, ficando a área útil da parcela para coleta dos dados com 13,2 $\mathrm{m}^{2}$ e com três linhas contendo 21 plantas cada uma, perfazendo um total de 63 plantas por parcela. 
Antes do preparo do solo, foram retiradas amostras das áreas experimentais para análise química do solo no Laboratório Central Analítica (Tabela 1).

Tabela 1. Análise química do solo das áreas da Estação Experimental da EMATER antes da instalação do experimento em Santana do Ipanema e São José da Tapera, respectivamente 2013.

\begin{tabular}{|c|c|c|c|c|c|c|c|c|c|}
\hline $\mathrm{pH}$ & $\mathrm{Na}$ & $\mathrm{P}$ & K & $\mathrm{Ca}+\mathrm{Mg}$ & $\mathrm{Al}$ & $\mathrm{H}+\mathrm{Al}$ & $\mathrm{S}$ & $\mathrm{T}$ & V \\
\hline $\mathrm{H}_{2} \mathrm{O}$ & --- & $--p$ & ----- & ------ & ----- & $\mathrm{q} / 100 \mathrm{~m}$ & ------ & & $\%$ \\
\hline \multicolumn{10}{|c|}{ Santana do Ipanema } \\
\hline 6,6 & 18 & 60 & 130 & 4,0 & 0,0 & 2,1 & 4,41 & 6,51 & 67,7 \\
\hline \multicolumn{10}{|c|}{ São José da Tapera } \\
\hline 6,5 & 88 & 8 & 110 & 3,4 & 0,01 & 0,5 & 4,06 & 4,56 & 89 \\
\hline
\end{tabular}

Fonte: Central Analítica Ltda, Maceió-AL.

No preparo do solo foram efetuadas uma aração e uma gradagem e logo após, foram abertos os sulcos de plantio e feita adubação de fundação, em que foi aplicado $10 \mathrm{t} \mathrm{ha}^{-1} \mathrm{de}$ esterco de bovino no fundo dos sulcos, em seguida os sulcos foram cobertos com uma camada de solo para a semente não entrar em contato direto com o esterco. Nos dois experimentos a semeadura foi realizada de forma manual, obedecendo ao espaçamento preconizado de 1,0 metro entre linhas e 0,2 metros entre covas, deixando três sementes por cova ao longo de cada suco de $5 \mathrm{~m}$. O desbaste das plantas foi feito aos 15 dias após a emergência das plântulas, deixando-se apenas uma planta por cova e cinco plantas por metro linear, perfazendo o total de 125 plantas por parcela. Em Santana do Ipanema para controle da lagarta do cartucho (Spodoptera frugiperda) foi utilizado inseticida com o princípio ativo deltametrina $25 \mathrm{~g} \mathrm{~L}$, na dosagem de $0,2 \mathrm{~L} \mathrm{ha}^{-1}$, em quatro aplicações, aos 8 , 16, 24 e 40 dias após a emergência das plantas, já em São José da Tapera o controle da lagarta do cartucho foi realizado através do óleo de neem, na dosagem de $0,2 \mathrm{~L} \mathrm{ha}^{-1} \mathrm{e}$, também, 0,5 $\mathrm{L} \mathrm{ha}^{-1}$ de urina de vacas em quatro aplicações: sendo duas de óleo neem, aos 8 e 12 dias, e duas de urina de vaca, aos 20 e 35 dias, respectivamente, após a emergência das plantas.

O controle das ervas daninhas foi realizado através de capina manual com três operações ao decorrer do ciclo da cultura.

Os experimentos foram conduzidos em sistema de sequeiro que é mais usual quando da implantação das lavouras pelos agricultores familiares do sertão alagoano. Durante o período de cultivo dos experimentos houve uma forte estiagem em toda região, onde a precipitação pluviométrica acumulada, da data de plantio até a colheita, foi de apenas 337,9 mm (Figura 1). 


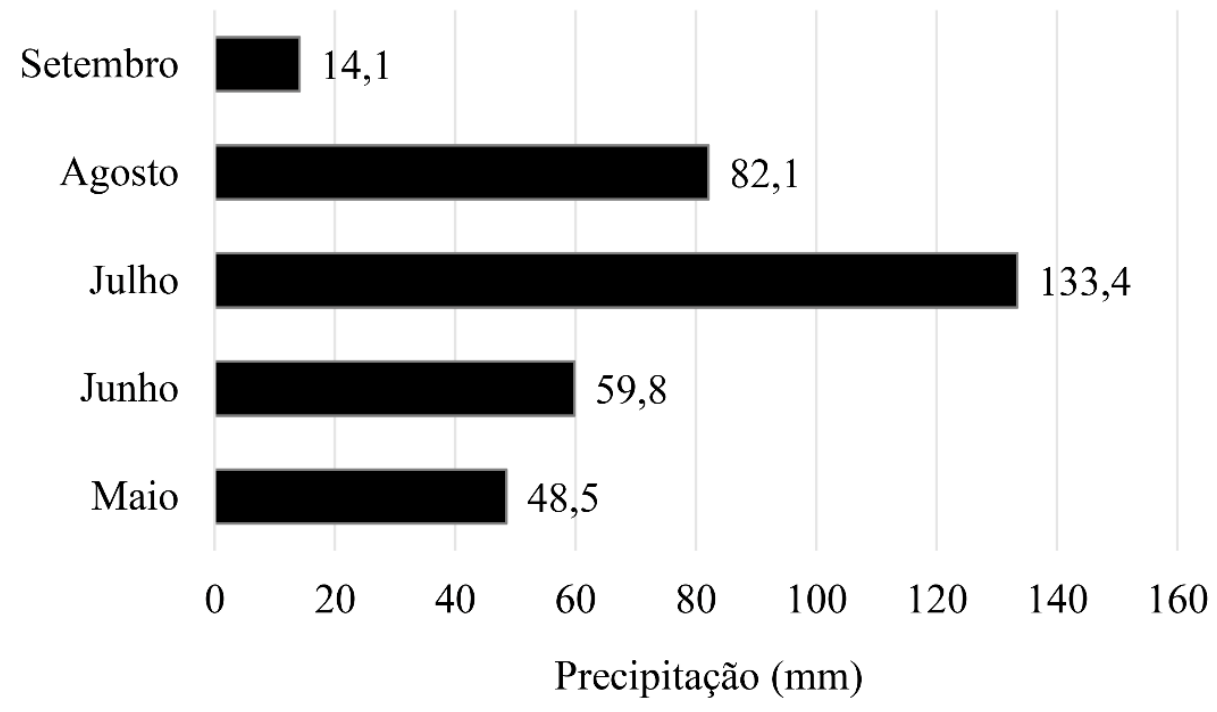

Figura 1. Precipitação mensal em mm durante a condução do experimento.

Fonte: Secretaria de Estado do Meio Ambiente e dos Recursos Hídricos, Maceió-AL.

As colheitas foram realizadas aos 130 dias após o plantio, as variáveis avaliadas foram: Diâmetro de Colmo (DC): (medido a $10 \mathrm{~cm}$ do solo com o uso de paquímetro em mm. Média de 18 plantas por parcela); Altura de Inserção da Primeira Espiga (AIPE): (medida com o auxílio de uma trena, considerando-se a distância do colo da planta ao ponto de inserção da primeira espiga formada, expressa $\mathrm{em} \mathrm{cm}$. Média de 18 plantas por parcela); Altura de Planta (AP): (medida com o auxílio de uma trena, considerando-se a distância do colo da planta ao ápice do pendão, expresso $\mathrm{em} \mathrm{cm}$. Média de18 plantas por parcela); Empalhamento da Espiga (EMPE): (determinada com auxílio de um esquadro milimetrado, através da diferença entre comprimento de espiga com palha e comprimento da espiga sem palha. Média das 18 espigas por parcela); Número de Fileiras de Grãos (NFG): (contagem do número de fileiras de grãos por espiga, de 18 plantas previamente selecionadas, de onde foram retiradas a média expressa em unidades); Peso de Cem Grãos (P100G): (medida do peso médio de cem grãos tomados ao acaso com o auxílio de uma balança de precisão, coletadas de 18 plantas previamente selecionadas. Peso corrigido para $13 \%$ de umidade e expresso em g); Rendimento de Grãos (RG): (determinado com o auxílio de uma balança de precisão, onde foram pesadas todas as sementes retiradas de todas as espigas das plantas da área útil de cada parcela. Peso corrigido para $13 \%$ de umidade e expresso em $\mathrm{kg} \mathrm{ha}^{-1}$ ). Rendimento da Matéria Seca (RMS): (determinado com auxílio da balança digital, sendo coletado no campo o peso das plantas e no laboratório o peso da palha e do sabugo após a debulha das espigas. Peso expresso em $\mathrm{kg} \mathrm{ha}^{-1}$ ). Para as características avaliadas: Diâmetro do Colmo, Altura da Planta, Altura de Inserção da Primeira Espiga, Empalhamento da Espiga, Número de Fileiras de Grãos e Peso de 100 Grãos foram realizadas as análises de variância do experimento por local de instalação usando o aplicativo SISVAR.

Logo após se procedeu a análise conjunta dos experimentos. Para as características avaliadas: Rendimento de Grãos e Rendimento da Matéria Seca foram realizadas previamente as análises de covariância para a correção das falhas. Após a realização das

Cultura Agronômica, Ilha Solteira, v.26, n.4, p.611-624, 2017 
análises de covariância por local do experimento foram realizadas as análises de variâncias para cada experimento, em que foi realizado o teste da homogeneidade de variâncias residuais para possibilitar a realização da análise conjunta. Sendo as variâncias residuais homogêneas, fez-se a análise de variância conjuntas dos experimentos. Para comparação das médias de todas as características avaliadas dos genótipos, foi utilizado o Teste de Tukey a $5 \%$ de probabilidade (FERREIRA, 2000).

\section{RESULTADOS E DISCUSSÃO}

Na Tabela 2 são apresentados os dados das análises de variância conjunta para as características avaliadas dos genótipos de milho em dois municípios do sertão alagoano, aos 130 dias após o plantio. Pelo teste F, constata-se que para as características AIPE, AP, NFG, EMPE e RMS houve diferença significativa entre os genótipos analisados a $1 \%$ de probabilidade. Já para as características DC e P100G, houve diferença significativa entre os genótipos analisados a $5 \%$ de probabilidade. Enquanto que para a variável RG, não houve diferença significativa a $5 \%$ de probabilidade entre os genótipos analisados.

Tabela 2. Resumo das análises da variância conjunta das variáveis analisadas de genótipos de milho em dois municípios do sertão alagoano. Rio Largo-AL, 2013.

\begin{tabular}{cccccccccc}
\hline \multirow{2}{*}{ CV } & \multicolumn{7}{c}{ QM $^{1}$} \\
\cline { 2 - 9 } & GL & AIPE $^{2}$ & AP & DC & NFG & EMPE P100G & RG & RMS \\
\hline G & 8 & $5.0004,7^{* *}$ & $7.911,4^{* *}$ & $16,1^{*}$ & $5,8^{* *}$ & $1,9^{* *}$ & $49,9^{*}$ & $366.174,5^{\text {ns }}$ & $5.794 .709,2^{* *}$ \\
L & 1 & $22.459,1^{* *}$ & $27.218,3^{* *}$ & $313,8^{* *}$ & $3,1^{*}$ & $6,1^{* *}$ & $9,8^{\text {ns }}$ & $3.406 .106,3^{*}$ & $29.878 .758,47^{* *}$ \\
G x L & 8 & $124,8^{\text {ns }}$ & $164,2^{\text {ns }}$ & $0,7^{\text {ns }}$ & $0,3^{\text {ns }}$ & $0,2^{\text {ns }}$ & $8,5^{\text {ns }}$ & $396.212,4^{* *}$ & $728.576,69^{\text {ns }}$ \\
RM & 32 & 98,8 & 200,1 & 0,9 & 0,2 & 0,3 & 5,8 & $88.483,6$ & $561.640,6$ \\
\hline & & & & & CV & & & \\
\hline SI & 9,92 & 6,55 & 7,00 & 4,19 & 6,64 & 9,23 & 14,31 & 20,57 \\
SJT & 7,92 & 5,08 & 4,83 & 3,81 & 12,04 & 6,67 & 7,76 & 14,43 \\
\hline
\end{tabular}

CV: Causa de variação; G: Genótipos; L: Locais; G x L: Interação; RM: Resíduo Médio; SI: S. do Ipanema; SJT: S. J. da Tapera; QM: Quadrado médio; GL: Graus de Liberdade e CV Coeficiente de Variação. Variáveis analisadas: AIPE: Altura de Inserção de Primeira Espiga, AP: Altura da Planta; DC: Diâmetro do Colmo; NFG: Número de Fileiras de Grãos; EMPE: Empalhamento da Espiga; P100G: Peso de cem Grãos; RG: Rendimento de Grãos; RMS: Rendimento de Matéria Seca. ns: Não significativo a $5 \%$ de probabilidade pelo teste F; **: Significativo a $1 \%$ de probabilidade pelo teste F; *: Significativo a $5 \%$ de probabilidade pelo teste F.

Para causa de variação de locais, pelo teste " $F$ " houve diferença significativa a $1 \%$ de probabilidade para as variáveis: AIPE, AP, DC, EMPE e RMS enquanto que para as variáveis NFG e RG houve diferença significativa a $5 \%$ de probabilidade para os genótipos analisados. E para a variável P100G, não houve diferença significativa a $5 \%$ de probabilidade entre os genótipos analisados.

Cultura Agronômica, Ilha Solteira, v.26, n.4, p.611-624, 2017 
A interação entre genótipos x locais não foi significativo para as variáveis: AIPE, AP, DC, NFG, EMPE, P100G e RMS, indicando que os comportamentos dos genótipos avaliados para essas variáveis não dependem dos locais onde foram cultivados. Para a variável RG, houve interação significativa entre genótipos e ambiente, no nível de significância de1 \% de probabilidade, indicando que existe uma dependência do genótipo em relação aos locais onde os mesmos foram cultivados.

Os coeficientes de variação para as variáveis analisadas nos dois experimentos variaram entre $3,81 \%$ e 20,57\%. Das oito variáveis analisadas, nos dois experimentos, 75 $\%$ dos CVs ficaram abaixo de $10 \%$, indicando uma ótima precisão experimental (FERREIRA, 2000).

$\mathrm{Na}$ Tabela 3 encontram-se as comparações das médias das seguintes variáveis: Altura de Inserção de Primeira Espiga, Altura da Planta, Diâmetro do Colmo, Número de Fileiras de Grãos, Empalhamento da Espiga, Peso de Cem Grãos e Rendimento de Matéria Seca, as quais foram mensuradas nos genótipos de milho aos 130 dias após o plantio que não apresentaram interação significativa entre genótipos e locais.

Tabela 3. Médias das variáveis avaliadas em genótipos de milho que não apresentaram interação significativa entre genótipos e locais. Rio Largo-AL, 2013.

\begin{tabular}{|c|c|c|c|c|c|c|c|}
\hline GENÓTIPOS $^{1}$ & $\begin{array}{l}\text { AP } \\
(\mathrm{cm})\end{array}$ & $\begin{array}{l}\text { AIPE } \\
(\mathrm{cm})\end{array}$ & $\begin{array}{c}\mathrm{DC} \\
(\mathrm{mm})\end{array}$ & $\begin{array}{c}\text { EMPE } \\
(\mathrm{cm})\end{array}$ & $\begin{array}{l}\text { NFG } \\
\text { (uni.) }\end{array}$ & $\begin{array}{c}\text { P100G } \\
(\mathrm{g})\end{array}$ & $\begin{array}{c}\text { RMS } \\
\left(\mathrm{kg} \mathrm{ha}^{-1}\right)\end{array}$ \\
\hline Branca & $280,08 b c$ & $125,62 b c$ & $18,56 \mathrm{c}$ & $7,12 b$ & $12,27 \mathrm{bc}$ & $28,73 a$ & $5.296,66$ bc \\
\hline Viçosense & $254,70 b c$ & $117,45 b$ & $17,58 \mathrm{c}$ & $6,44 a b$ & $11,78 b$ & $28,65 a$ & $4.249,90 \mathrm{abc}$ \\
\hline Asa Branca & $198,74 a$ & $70,20 \mathrm{a}$ & $15,18 \mathrm{ab}$ & $5,83 a$ & $12,70 \mathrm{bc}$ & $29,11 \mathrm{a}$ & $3.310,24 \mathrm{ab}$ \\
\hline Batité & $252,51 b$ & $123,30 b c$ & $18,13 \mathrm{c}$ & $6,61 \mathrm{ab}$ & $11,50 \mathrm{~b}$ & $28,11 \mathrm{a}$ & $4.439,23 \mathrm{abc}$ \\
\hline São Luiz & $256,33 b c$ & $121,23 b$ & $17,24 \mathrm{c}$ & $6,87 \mathrm{ab}$ & $11,92 b c$ & $28,34 \mathrm{a}$ & $4.525,27 \mathrm{abc}$ \\
\hline Jabotão & $284,21 \mathrm{c}$ & $147,79 \mathrm{c}$ & $18,30 \mathrm{c}$ & $6,98 \mathrm{ab}$ & $10,75 \mathrm{ab}$ & $36,33 b$ & $5.842,54 \mathrm{c}$ \\
\hline Alagoano & $257,36 b c$ & $121,78 b c$ & $16,94 b c$ & $7,60 \mathrm{~b}$ & $11,81 b c$ & $29,50 \mathrm{ab}$ & $4.517,07 \mathrm{abc}$ \\
\hline Branco & $255,76 b c$ & $125,62 b c$ & $18,12 \mathrm{c}$ & 6,63ab & $9,82 \mathrm{a}$ & $34,00 \mathrm{~b}$ & $4.951,55 \mathrm{bc}$ \\
\hline Assum Preto & $173,55 \mathrm{a}$ & $60,26 a$ & $13,67 \mathrm{a}$ & $5,86^{\mathrm{a}}$ & $13,10 \mathrm{c}$ & $29,49 \mathrm{ab}$ & $2.584,07 \mathrm{a}$ \\
\hline$\Delta_{5 \%}{ }^{4}$ & 30,19 & 26,32 & 2,0 & 1,24 & 1,29 & 6,90 & $2.010,66$ \\
\hline
\end{tabular}

Asa Branca e Assum Preto - Variedades Comerciais / Embrapa; Branca, Viçosense, São Luiz e Alagoano Populações Alagoanas; Batité, Jabotão e Branco - Variedades Crioulas. AP: Altura da Planta; AIPE: Altura de Inserção de Primeira Espiga, DC: Diâmetro do Colmo; EMPE: Empalhamento da Espiga; NFG: Número de Fileiras de Grãos; P100G: Peso de cem Grãos; RMS: Rendimento de Matéria Seca. Médias seguidas pela mesma letra, em cada coluna, não diferem entre si pelo teste de Tukey a $5 \%$ de probabilidade.

Quanto ao porte da planta, a variedade crioula Jabotão apresentou a maior altura de planta, mas não diferiu estatisticamente da variedade crioula Branco nem das populações de polinização livre Branca, Viçosense, São Luiz e Alagoano. As variedades comerciais desenvolvidas pela Embrapa apresentaram a menor altura de planta, não diferiram entre si, mas diferiram de todos os outros genótipos. 
De forma semelhante à altura da planta, a variedade crioula Jabotão apresentou a maior altura de inserção da primeira espiga (AIPE). A mesma não diferiu estatisticamente das variedades crioulas, Branco e Batité, nem das populações Branca e Alagoano. As variedades comerciais disponibilizadas pela EMBRAPA não diferiram entre si e apresentaram as menores alturas para AIPE.

Quanto ao empalhamento das espigas, as populações Alagoano e Branca apresentaram as melhores coberturas das espigas. Enquanto as variedades comerciais Asa Branca e Assum Preto (EMBRAPA) apresentaram as menores coberturas das espigas. Os demais genótipos de milho se situaram numa posição intermediária.

A secagem natural do milho na planta é realizada pelos agricultores alagoanos, mesmo aqueles que fazem a colheita mecânica do milho. Esse método pode prejudicar a qualidade do milho pela exposição as condições climáticas, sobretudo precipitação e umidade além das pragas e doenças que atacam a cultura nesse estádio fenológico. Uma forma de reduzir essas perdas seria a utilização de variedades que apresentam um bom empalhamento. Para Schuh et al. (2011), o empalhamento de espigas é um caráter importante para reduzir perdas de milho. O bom empalhamento permite boa cobertura da ponta da espiga, evitando danos por insetos e por fungos que propiciam a ocorrência de grãos ardidos (RODRIGUES et al., 2009). As espigas com características de decumbência e de bom empalhamento apresentaram as menores incidências de grãos ardidos, sendo consideradas espigas bem empalhadas, aquelas onde as palhas protegem muito bem os grãos, estendendo-se por dois ou mais centímetros além da ponta do sabugo (PIMENTEL et al., 2011; LIMA et al., 2015). Mesmo ocorrendo diferença entre os genótipos avaliados, todos apresentaram um bom empalhamento, onde a palha ultrapassou pelo menos cinco centímetros além da ponta do sabugo.

Para a variável NFG, a variedade comercial Assum Preto da Embrapa apresentou o maior valor médio, mas não diferiu estatisticamente da variedade Asa Branca, também desenvolvida pela EMBRAPA, e das populações de polinização livre: Branca, São Luiz e Alagoano. A variedade crioula Branco apresentou o menor valor médio, não diferindo da variedade crioula Jabotão, mas deferiu das demais.

Para P100G, a variedade crioula Jabotão apresentou o maior valor médio e não diferiu da variedade crioula Branca, do genótipo Alagoano e nem da variedade comercial Assum Preto. A variedade crioula Batité apresentou o menor valor médio e não diferiu estatisticamente das populações alagoanas: Branca, Viçosense, São Luiz e Alagoano nem das variedades comerciais Assum Preto e Asa Branca.

Segundo Cargnelutti Filho et al. (2010), o número de fileiras e massa seca dos grãos tem correlação com a produção de grãos entre outras características. Para esses autores os resultados dependem das características dos genótipos avaliados e do ambiente onde os mesmos foram cultivados. 
Para a variável DC, o genótipo Branca do SMGP/CECA/UFAL apresentou o maior diâmetro de colmo e não diferiu estatisticamente das populações Alagoano, São Luiz e Viçosense, nem das variedades crioulas Branco, Batité e Jabotão. A variedade comercial Assum Preto apresentou o menor diâmetro de colmo e não diferiu da variedade Asa Branca, ambas desenvolvidas pela Embrapa.

O DC é importante característica morfológica, pois tem sido relacionado não só com a tolerância ao quebramento de plantas, mas também com a maior capacidade da planta em armazenar fotoassimilados que contribuirão com o enchimento dos grãos, ou seja, com aumento da produtividade (FRANCELLI; DOURADO NETO, 2008; KAPPES et al., 2013).

Diferente do agronegócio que possui uma única atividade, a agricultura familiar desenvolve várias atividades ao mesmo tempo em seus estabelecimentos. Essa é uma das estratégias de sustentabilidade das propriedades da agricultura familiar, a diversificação das atividades e a interação que existe entre elas. Além das lavouras temporárias como o feijão e o milho, o agricultor familiar cria aves, bovinos e ovinos. Para alimentação dos ruminantes é utilizada as mais diferentes fontes de volumosos como pastagens, palma forrageira, silagem e restos culturais do milho e do feijão. Os restos culturais também denominados de palhada é o resíduo agrícola que na cultura do milho correspondente à parte aérea da planta sem as espigas, seca naturalmente a campo (SANTOS et al., 2014).

Devido à baixa e irregular precipitação verificada durante o cultivo do milho, houve redução no desenvolvimento da cultura tanto para o caráter produção de grãos quanto produção de biomassa. Segundo Bonfim-Silva et al. (2011), o déficit hídrico reduz o crescimento do milho, em função de decréscimos da área foliar e da biomassa.

Quanto à variável RMS, a variedade crioula Jabotão apresentou o maior valor de matéria seca de milho, mas diferiu estatisticamente apenas das variedades comerciais Assum Preto e Asa Branca que apresentaram os menores rendimentos. A variedades crioula Batité e as populações alagoanas Viçosense, São Luiz e Alagoano tiveram um desempenho intermediário e ambíguo, pois, não diferiram estatisticamente da variedade crioula Jabotão nem, das variedades comerciais Assum Preto e Asa Branca. Dos genótipos de milho avaliados, as variedades crioulas e as populações alagoanas tiveram um ótimo desempenho de matéria seca da palhada de milho (planta inteira sem espiga, palha da espiga e sabugo), superando, em média, mais de $60 \%$ a produção de grãos.

Na Tabela 4 constam as médias dos genótipos de milho para a variável Rendimento de Grãos que apresentou interação significativa entre genótipos e locais.

Em Santana do Ipanema, o genótipo Branca, desenvolvido pelo SMGP/CECA/UFAL, apresentou o melhor rendimento, mas não diferiu das populações de polinização livre Viçosense e São Luiz; das variedades crioulas Batité, Jabotão e Branco; e da variedade comercial Asa Branca. A população Alagoano, desenvolvido pelo SMGP/CECA/UFAL, apresentou o menor rendimento e não diferiu estatisticamente das variedades comerciais Asa Branca e Assum Preto, e das variedades crioulas Batité e Branco. Em São José da 
Tapera, o genótipo que apresentou o melhor rendimento foi à variedade comercial Asa Branca, diferindo estatisticamente apenas da variedade crioula Batité, que apresentou o menor rendimento. As populações Branca, Viçosense, São Luiz e Alagoano, as Variedades crioulas Jabotão e Branco, e a variedade comercial Assum Preto apresentaram ambiguidade, ou seja, não diferiram da variedade Asa Branca, nem da variedade crioula Batité.

Tabela 4. Médias de Rendimento de grãos (RG) de genótipos de milho. Rio Largo-AL, 2013.

\begin{tabular}{lrc}
\hline \multicolumn{1}{c}{ GENÓTIPOS } & \multicolumn{2}{c}{${\text { RG }\left(\mathrm{kg} \mathrm{ha}^{-1}\right)}^{1}$} \\
\cline { 2 - 3 } & S. Ipanema & S. J. da Tapera \\
\hline Branca & $3.022,50 \mathrm{c}^{2}$ & $3.022,69 \mathrm{ab}$ \\
Viçosense & $2.625,59 \mathrm{bc}$ & $2.999,19 \mathrm{ab}$ \\
Asa Branca & $2.577,22 \mathrm{abc}$ & $3.446,10 \mathrm{~b}$ \\
Batité & $2.365,49 \mathrm{abc}$ & $2.502,45 \mathrm{a}$ \\
São Luiz & $2.683,48 \mathrm{bc}$ & $2.881,91 \mathrm{ab}$ \\
Jabotão & $2.918,77 \mathrm{c}$ & $2.697,96 \mathrm{ab}$ \\
Alagoano & $1.793,40 \mathrm{a}$ & $2.901,97 \mathrm{ab}$ \\
Branco & $2.234,38 \mathrm{abc}$ & $3.289,14 \mathrm{ab}$ \\
Assum Preto & $1.935,07 \mathrm{ab}$ & $2.955,17 \mathrm{ab}$ \\
\hline
\end{tabular}

$\Delta_{5 \%}{ }^{2} \quad 810,61$

${ }^{1}$ Asa Branca e Assum Preto - Variedades Comerciais / Embrapa; Branca, Viçosense, São Luiz e Alagoano Populações Alagoanas; Batité, Jabotão e Branco Variedades Crioulas. ${ }^{2}$ Médias seguidas pela mesma letra, em cada coluna, não diferem entre si pelo teste de Tukey a $5 \%$ de probabilidade.

Abreu et al. (2007) em trabalho realizado no município de Chapecó, constatou para aquelas condições e com os genótipos avaliados que as variedades crioulas apresentaram resultados semelhantes ao hídrido DKB 350.

A rentabilidade obtida na cultura do milho com as variedades crioulas é superior a alcançada nos sistemas convencionais empregados na agricultura brasileira, principalmente por não necessitar de elevados investimentos em insumos para alcançar elevadas produtividades como na agricultura convencional, sendo uma alternativa viável para agricultura familiar que não dispõe de recursos para investir nas lavouras (SANDRI; TOFANELLI, 2008).

Para Guadagnin et al., (2009), realizando o melhoramento participativo de variedades locais, concluíram que os resultados demonstram a viabilidade econômica de sistemas produtivos com enfoque agroecológico que utilizam variedades locais de milho, além das inegáveis vantagens socioambientais.

Trabalhando com variedades crioulas e híbridos, Coimbra et al. (2010) concluíram que as variedades crioulas possuem potencial de produtividade similar aos híbridos. Já Carpentieri-Pípolo (2010), conduzindo experimento com populações crioulas e variedades comerciais em sistema de baixo nível tecnológico, concluiu que as variedades crioulas P-13, P-15 e P-05 demonstraram potencial produtivo elevado. Contudo, Miranda et al. (2007) 
explicam que as variedades crioulas são viáveis técnica e economicamente, mas se utilizada de forma isolada não resolve o problema da agricultura familiar.

Os resultados desses experimentos discordam de alguns autores que afirmam que as variedades crioulas são inferiores no que diz respeito à produção de grãos. Para chegar a essa conclusão, deve-se levar em conta os materiais utilizados, os locais onde são desenvolvidos os experimentos e qual o nível tecnológico empregado para que sejam tiradas as devidas conclusões.

Considerando os locais avaliados e o nível tecnológico utilizado, as populações de polinização livre Branca, Viçosense e São Luiz, e as variedades crioulas Jabotão e Branco e a variedade comercial Asa Branca apresentaram bons resultados, quanto ao rendimento de grãos, superando, em média, em torno de $300 \%$ o rendimento médio de grãos do Estado de Alagoas (Tabela 5).

Tabela 5. Médias das sete variáveis avaliadas em relação aos dois municípios que apresentaram diferença significativa entre os locais de realização dos experimentos. Rio Largo-AL, 2013.

\begin{tabular}{ccccccccc}
\hline MUNICÍPIO & $\begin{array}{c}\text { AP } \\
(\mathrm{cm})\end{array}$ & $\begin{array}{c}\text { AIPE } \\
(\mathrm{cm})\end{array}$ & $\begin{array}{c}\text { DC } \\
(\mathrm{mm})\end{array}$ & NFG & $\begin{array}{c}\text { EMPE } \\
(\mathrm{cm})\end{array}$ & P100G & $\begin{array}{c}\text { RG } \\
\left(\mathrm{kg} \mathrm{ha}^{-1}\right)\end{array}$ & $\begin{array}{c}\text { RMS } \\
\left(\mathrm{kg} \mathrm{ha}^{-1}\right)\end{array}$ \\
\hline $\begin{array}{c}\text { Santana do } \\
\text { Ipanema }\end{array}$ & $223,47 \mathrm{a}$ & $93,07 \mathrm{a}$ & $14,67 \mathrm{a}$ & $11,50 \mathrm{a}$ & $6,99 \mathrm{~b}$ & $805,23 \mathrm{a}$ & $2.461,77 \mathrm{a}$ & $3.669,10 \mathrm{a}$ \\
$\begin{array}{c}\text { São José da } \\
\text { Tapera }\end{array}$ & $268,37 \mathrm{~b}$ & $133,86 \mathrm{~b}$ & $19,49 \mathrm{~b}$ & $11,98 \mathrm{~b}$ & $6,32 \mathrm{a}$ & $828,25 \mathrm{a}$ & $2.964,07 \mathrm{~b}$ & $5.156,79 \mathrm{~b}$ \\
\hline
\end{tabular}

Variáveis analisadas: AP: Altura da Planta; AIPE: Altura de Inserção de Primeira Espiga; DC: Diâmetro do Colmo; NFG: Número de Fileiras de Grãos; EMPE: Empalhamento da Espiga; RG: Rendimento de Grãos; RMS: Rendimento de Matéria Seca. Médias seguidas pela mesma letra, em cada coluna, não diferem entre si pelo teste de $\mathrm{F}$ a $5 \%$ de probabilidade.

Observa-se que o município de São José da Tapera, apresentou um melhor desempenho nas seguintes variáveis: AP, AIPE, DC, NFG, RG e RMS. Variáveis essas, correlacionadas diretamente tanto com a produção de grãos quanto a produção de matéria seca. Já o município de Santana do Ipanema apresentou melhor desempenho apenas para o caráter empalhamento das espigas.

Esses resultados indicam que as condições ambientais: tipo de solo, precipitação, temperatura, umidade, observadas na propriedade localizada em São José da Tapera, foram mais favoráveis para o desenvolvimento da cultura do milho, do que as condições observadas na estação experimental da EMATER-AL, em Santana do Ipanema durante o ano de 2013.

Cultura Agronômica, Ilha Solteira, v.26, n.4, p.611-624, 2017 


\section{CONCLUSÃO}

Os genótipos Branca, Asa Branca e Branco apresentaram em São José da Tapera rendimentos de grãos, superiores a $3.000 \mathrm{~kg} \mathrm{ha}^{-1}$ e em Santana do Ipanema apenas o genótipo Branca atingiu tal rendimento.

As populações de polinização livre e as variedades crioulas apresentaram um porte mais alto, uma maior altura de inserção da primeira espiga e um maior diâmetro de colmo que as variedades comerciais, proporcionando um maior rendimento de matéria seca nos dois ambientes.

Nos dois ambientes, a população Branca e a variedade crioula Jabotão tiveram um bom desempenho produtivo de matéria seca, com rendimentos médios acima de $5.000 \mathrm{~kg}$ $\mathrm{ha}^{-1}$.

A população Branca apresentou dupla aptidão (melhor rendimento de grãos e de matéria seca) se destacando dos demais genótipos nos ambientes analisados.

\section{REFERÊNCIAS BIBLIOGRÁFICAS}

ABREU, L.; CANSI, E.; JURIATTI, C. Avaliação do rendimento socio-econômico de variedades crioulas e hibridos comerciais de milho na microregião de chapecó. Revista Brasileira de Agroecologia, Pelotas, v. 2, n. 1, p.1-4, 2007.

ALVARES, C. A.; STAPE J. L.; SENTElHAS, P. C.; GONÇALVES, J. L. M.; SPAROVEK, G. Köppen's climate classification map for Brazil. Meteorologische Zeitschrift, Stuttgart, v. 22, n. 6, p.711-728, 2014.

BECKER, C.; ANJOS, F. S. Segurança alimentar e desenvolvimento rural: limites e possibilidades do programa de aquisição de alimentos da agricultura familiar, em municípios do sul gaúcho. Segurança Alimentar e Nutricional, Campinas, v. 17, n. 1, p.61-72, 2010.

BONFIM-SILVA, E. M.; SILVA, T. J. A.; CABRAL, C. E. A.; KROTH, B. E.; REZENDE, D. Desenvolvimento inicial de gramíneas submetidas ao estresse hídrico. Revista Caatinga, Mossoró, v. 24, n. 2, p.180-186, 2011.

BRAMBILlA, J. A.; LANGE, A.; BUCHELT, A. C.; MASSAROTO, J. A. Produtividade de milho safrinha no sistema de integração lavoura-pecuária, na região de Sorriso, Mato Grosso. Revista Brasileira de Milho e Sorgo, Sete Lagoas, v. 8, n. 3, p.263-274, 2009.

CARGNELUTTI FILHO, A.; TOEBE, M.; BURIN, C.; SILVEIRA, T. R.; CASAROTTO, G. Tamanho de amostra para estimação do coeficiente de correlação linear de Pearson entre caracteres de milho. Pesquisa Agropecuári Brasileira, Brasilia, v. 45, n. 12, p.1363-1371, 2010 .

Cultura Agronômica, Ilha Solteira, v.26, n.4, p.611-624, 2017 
CARPENTIERI-PÍPOLO, V.; SOUZA, A.; SILVA, D. A.; BARRETO, T. P.; GARBUGLIO, D. D.; FERREIRA, J. M. Avaliação de cultivares de milho crioulo em sistema de baixo nível tecnológico. Acta Scientiarum Agronomy, Maringá, v. 32, n. 2, p.229-233, 2010.

COIMBRA, R. R.; MIRANDA, G. V.; CRUZ, C. D.; MELO, A. V.; ECKERT, F. R. Caracterização e divergência genética de populações de milho resgatadas do Sudeste de Minas Gerais. Revista Ciência Agronômica, Fortaleza, v. 41, n. 1, p.159-166, 2010.

FERREIRA, P. V. Estatística experimental aplicada à agronomia. 1. ed. Maceió: Edufal, 2000. $422 \mathrm{p}$.

FRANCELli, A. L.; DOURADO NETO, D. Produção de milho. 1. ed. Piracicaba: Ceres, 2008. $360 \mathrm{p}$.

GUADAGNIN, C. A.; GUADAGNIN, C. M. I.; CANCI, A. Melhoramento participativo de variedades locais de milho nas associações de desenvolvimento das microbacias de Guaraciaba - SC. Revista Brasileira de Agroecologia, Pelotas, v. 4, n. 1, p.993-996, 2009.

INSTITUTO BRASILEIRO DE GEOGRAFIA E ESTATÍSTICA - IBGE. Versão Eletrônica. 2013. Disponível em: http://www.ibge.gov.br/estadosat/. Acesso em: $01 \mathrm{dez}$. 2016.

KAPPES, C.; ARF, O.; ANDRADE, J. A. C. Produtividade do milho em condições de diferentes manejos do solo e de doses de nitrogênio. Revista Brasileira Ciências do Solo, Viçosa, v. 37, n. 5, p.1310-1321, 2013.

LIMA, L. G.; ASSMANN, E. J. Desfolha causada pela Spodoptera frugiperda em milho com diferentes biotecnologias. Revista Cultivando o Saber, Cascavel, v. 8, n. 5, p.56-66, 2015.

MADAlENA, J. A. S.; FERREIRA, P. V.; ARAÚJO, E.; CUNHA, J. L. X. L.; LINHARES, P. C. F. Seleção de genótipos de milho (Zea mays L.) submetidos a quatro densidades de semeadura no município de Rio Largo - AL. Caatinga, Mossoró, v. 22, n. 1, p.48-58, 2009.

MIRANDA, G. V.; SOUZA, L. V.; SANTOS, I. C.; MENDES, F. F. Resgate de variedades crioulas de milho na região de Viçosa-MG. Revista Brasileira de Agroecologia, Pelotas, v. 2, n. 1, p.1145-1148, 2007.

PIMENTEL, M. A. G.; MENDES, S. M.; QUEIROZ, V. A. V.; COSTA, R. V. da; ALBERNAZ, W. M. Impacto da seleção de espigas de milho na infestação por carunchos durante o armazenamento em propriedades familiares do estado de Minas Gerais. Revista Brasileira de Agroecologia, Pelotas, v. 6, n. 2, p.1-5, 2011.

QUEIROZ, A. M.; SOUZA, C. H. E.; MACHADO, V. J.; LANA, R. M. Q.; KORNDORFER, G. H.; SILVA, A. A. Avaliação de diferentes fontes e doses de nitrogênio

Cultura Agronômica, Ilha Solteira, v.26, n.4, p.611-624, 2017 
na adubação da cultura do milho (zea mays L.). Revista Brasileira de Milho e Sorgo, Sete Lagoas, v. 10, n. 3, p.257-266, 2011.

RODRIGUES, F.; PINHO, R. G. V.; ALBUQUERQUE, C. J. B.; FARIA FILHO, E. M.; GOULART, J. C. Capacidade de combinação entre linhagens de milho visando à produção de milho verde. Bragantia, Campinas, v. 68, n. 1, p.75-84, 2009.

SANDRI, C. A.; TOFANELLI, M. B. D. Milho crioulo: uma alternativa para rentabilidade no campo. Pesquisa Agropecuária Tropical, Goiânia, v.38, n. 1, p.59-61, 2008.

SANTOS, F. C.; ALBUQUERQUE FILHO, M. R.; VILELA, L.; FERREIRA, G. B.; CARVALHO, M. C. S.; VIANA, J. H. M. Decomposição e liberação de macronutrientes da palhada de milho e braquiária, sob integração lavoura-pecuária no cerrado baiano. Revista Brasileira de Ciências do Solo, Viçosa, v. 38, n. 6, p.1855-1861, 2014.

SCHUH, G.; GOTTAEDI, R.; FERRARI FILHO, E.; ANTUNES, L. E. G.; DIONELLO, R. G. Efeitos de dois métodos de secagem sobre a qualidade físico-química de grãos de milho safrinha - RS, armazenados por 6 meses. Semina: Ciências Agrárias, Londrina, v. 32, n. 1, p.235-244, 2011.

VALDERRAMA, M.; BUZETTI, S.; BENETT, C. G. S.; ANDREOTTI, M.; TEIXEIRA FILHO, M. C. M. Fontes e doses de NPK em milho irrigado sob plantio direto. Pesquisa Agropecuaria Tropical, Goiânia, v. 41, n. 2, p.254-263, 2011. 